\title{
Identification of genomic copy number variations associated with specific clinical features of head and neck cancer
}

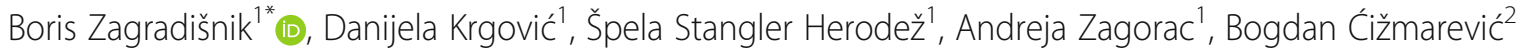 \\ and Nadja Kokalj Vokač ${ }^{1}$
}

\begin{abstract}
Background: Copy number variations (CNSs) of large genomic regions are an important mechanism implicated in the development of head and neck cancer, however, for most changes their exact role is not well understood. The aim of this study was to find possible associations between gains/losses of genomic regions and clinically distinct subgroups of head and neck cancer patients.

Results: Array comparative genomic hybridization (aCGH) analysis was performed on DNA samples in 64 patients with cancer in oral cavity, oropharynx or hypopharynx. Overlapping genomic regions created from gains and losses were used for statistical analysis. Following regions were overrepresented: in tumors with stage I or II a gain of 2. $98 \mathrm{Mb}$ on 6p21.2-p11 and a gain of 7.4 Mb on 8q11.1-q11.23; in tumors with grade I histology a gain of $1.1 \mathrm{Mb}$ on 8q24.13, a loss of a large part of $\mathrm{p}$ arm of chromosome 3, a loss of a $1.24 \mathrm{Mb}$ on $6 \mathrm{q} 14.3$, and a loss of terminal $32 \mathrm{Mb}$ region of 8p23.3; in cases with affected lymph nodes a gain of $0.75 \mathrm{Mb}$ on 3q24, and a gain of $0.9 \mathrm{Mb}$ on 3q26.32-q26. 33 ; in cases with unaffected lymph nodes a gain of $1.1 \mathrm{Mb}$ on 8q23.3, in patients not treated with surgery a gain of 12. $2 \mathrm{Mb}$ on 7q21.3-q22.3 and a gain of 0.33 Mb on 20q11.22.

Conclusions: Our study identified several genomic regions of interest which appear to be associated with various clinically distinct subgroups of head and neck cancer. They represent a potentially important source of biomarkers useful for the clinical management of head and neck cancer. In particular, the PIK3CA and AGTR1 genes could be singled out to predict the lymph node involvement.
\end{abstract}

Keywords: Head and neck cancer, Copy number variations, Array comparative genomic hybridization, Biomarkers

\section{Background}

The head and neck squamous cell carcinomas (HNSCCs) are among the most common cancers, affecting approximately 530,000 new patients and causing 293,000 deaths worldwide every year [1]. The overall survival rate of around $50 \%$ is an important indicator that this type of cancer represents a major medical problem [2]. An improvement in disease management can be expected from better understanding of molecular mechanisms underlying this medical condition. Acquired DNA mutations which range from epigenetic DNA methylation alterations, single

\footnotetext{
* Correspondence: boris.zagradisnik@ukc-mb.si

'Laboratory of Medical Genetics, University Medical Centre Maribor, Ljubljanska

5, 2000 Maribor, Slovenia

Full list of author information is available at the end of the article
}

nucleotide changes to variations in whole chromosomal copy number are a well-established cause of cancer. An important subset represent copy number variations (CNVs) which can include large chromosomal regions or gene-size changes [3-5]. Gains and losses of particular genomic segments usually contain important oncogenes and tumor suppressor genes. These include such regions as a gain of 11q13 (CCND1 gene, cyclin D1), a gain of $7 \mathrm{p} 11$ (EGFR gene, epidermal growth factor receptor), a loss of 9p (CDKN2A gene, cyclin dependent kinase 2a / p16), among many others $[3,6,7]$. The development of array comparative genomic hybridization provided further evidence for the role of frequent and characteristic gains and losses in HNSCCs. The accumulating data clearly reveal great heterogeneity apparent from a long list of 
genomic regions harboring gains $(1 \mathrm{q}, 3 \mathrm{p}, 3 \mathrm{q}, 5 \mathrm{p}, 7 \mathrm{p}, 7 \mathrm{q}$, $8 q, 9 q, 11 q, 14 q, 16 p, 19 q, 20 q)$ and losses (2p, 3p, 3q, 4q, 8p, 10p, 16q, 18q) [8-11]. These are all excellent tumor markers which when present clearly and unequivocally identify a tissue sample as cancerous. However, the adoption of CNV detection for other roles in disease management is not easy because data supporting associations with various clinical parameters are often sparse or even contradictory $[12,13]$. Consequently, these genetic biomarkers remain the interest of research with few of them nearing clinical practice of head and neck cancer treatment [14]. Nevertheless, they are of great importance in a quest to refine the current clinical description of tumors based on the TNM classification [15]. High heterogeneity exhibited by HNSCC may not always be sufficiently accounted for by the disease staging and pathomorphologic characterization. Therefore, it is important to continue the search for additional parameters which may help improve the categorization of individual cases of HNSCC. A hypothesis-free whole genome analysis is the modern approach to conduct such an examination [16].

This study identifies possible associations between gains/losses of genomic regions and clinical features characteristic for two distinct subgroups of head and neck cancer patients, those with early disease vs. those with loco-regionally advanced cancer.

\section{Methods}

\section{Patients}

The study included 64 patients (50 males, $78.1 \% ; 14$ females, $21.9 \%$ ) with the diagnosis of head and neck cancer located in oral cavity, oropharynx or hypopharynx, who underwent treatment at the Department of Otorhinolaryngology, Cervical and Maxillofacial Surgery, University Medical Centre Maribor, Slovenia. They were recruited between November 2010 and March 2015. Clinical information about age, gender, age at diagnosis, follow-up and survival time, and disease recurrence was collected from medical records. The stage of the disease was determined from the TNM status of the tumor; however, not all patients received surgical treatment and postoperative evaluation was not available for all tumors. Histologic grade was also obtained. In addition, the treatment regimens in patients were recorded as surgery, chemotherapy, radiotherapy or the combinations thereof.

This study was approved by the Ethics committee of the University Medical Centre Maribor, where the study was conducted. Each patient signed an informed consent prior to the study enrollment.

\section{Tumor samples}

Tumor samples were excised from primary tumor sites and not from metastatic sites or affected lymph nodes.
All samples were specimens for pathological confirmation following surgery or diagnostic biopsy of which a small part was obtained for the long term storage at $-80{ }^{\circ} \mathrm{C}$.

\section{DNA extraction}

At least $10 \mathrm{mg}$ of tumor tissue was thoroughly disrupted with the TissueLyzer (Qiagen G.m.b.h., Hilden, Germany). The lysate was then used for the extraction of genomic DNA with the Qiaamp DNA Mini Kit on QIACUBE (both Qiagen G.m.b.h., Hilden, Germany). All procedures were performed according to the manufacturer's instructions.

\section{Human papilloma virus detection}

In order to ascertain the presence of human papilloma virus (HPV) DNA in tumor samples a simple duplex polymerase chain reaction protocol was developed. A $10 \mu \mathrm{L}$ reaction contained $10 \mu \mathrm{M}$ of primers MY09 (5'CGTCCMARRGGAWACTGATC-3') and MY11 (5'-GC MCAGGGWCATAAYAATGG-3') [17], $1 \mu \mathrm{M}$ of control locus primers (Forward: 5'-CTATCCCACTGTATTATT CAGGGC-3'; Reverse: 5'-TGAGTCTCCAGGTTGCAG GTGACA-3'), $50 \mathrm{ng}$ of tumor genomic DNA in $1 \times$ Multiplex PCR Master Mix Kit (Qiagen G.m.b.h., Hilden, Germany). The temperature protocol was: $15 \mathrm{~min}$ of initial denaturation/enzyme activation at $95{ }^{\circ} \mathrm{C}$, followed by 35 cycles of $30 \mathrm{~s}$ denaturation at $94{ }^{\circ} \mathrm{C}, 1 \mathrm{~min}$ annealing at $55^{\circ} \mathrm{C}$ and 1 min elongation at $72{ }^{\circ} \mathrm{C}$. The amplification products were detected with agarose gel electrophoresis after staining with SYBR Green I.

\section{Array comparative genomic hybridization analysis}

Array $\mathrm{CCH}$ analysis was performed using the BlueGnome Cytochip ISCA $8 \times 60 \mathrm{~K}$ platform (BlueGnome Ltd. Cambridge, United Kingdom). The assay was performed according to the manufacturer's instructions. Data were obtained using the BlueFuse Multi software tool. Automatic assessment provided by the software was used to acquire genetic variations. A minimal size of 20,000 base pairs (20kbp) was adopted as an inclusion criterion. The data were arranged according to chromosomal location to obtain the extent and frequency of overlapping regions, which were then used for further analysis. Gains and losses were analyzed separately. The GRCh37/hg19 was used for genomic data analysis and representation.

\section{Statistical analysis}

The odds ratios (ORs) and chi-squared test (Chi2) with Yates correction were used to evaluate differences in copy number variation frequencies stratified by the patients' characteristics. Patients were grouped according to the disease stage (stage I \& II vs. stage III \& IV), 
histological grade (grade 1 vs. grade $2 \& 3$ ), tumor size (T1 \& T2 vs, T3 \& T4), lymph node involvement (cases $\mathrm{N} 0$ vs. cases $\mathrm{N} 1$ or higher) and surgical treatment (surgery used vs. no surgery used). A $2 \times 2$ contingency table was generated between each of the five clinical feature groups and each genomic region involved. 95\% confidence intervals $(\mathrm{CI})$ were computed where applicable and a $p$ value $<0.05$ was considered statistically significant. All analyses were done in OpenOffice, org Calc spreadsheet application.

\section{Results}

Our study included 64 patients, mostly men $(50,78.1 \%$, male to female ratio 3.57:1). with similar median age at diagnosis for both gender groups (Table 1). Since the study enrollment 42 patients have died (33 due to cancer, 9 from other causes) and 3 were lost to followup. Histologically verified squamous cell carcinoma was present in all patients. Most patients were affected with HNSCC for the first time; however, in 3 patients the cancer has re-occurred after a prolonged disease free interval. The tumors were positioned in oral cavity (34 patients), oropharynx (25 patients), and hypopharynx (5 patients) (Table 1), although for some large tumors their locations could not be precisely determined because they affected multiple adjacent anatomic regions. Most cancers were locally advanced (47 stage IV cases) and lymph node involvement was also frequent (42 cases) (Table 1$)$. Distant metastases were a rare event observed in 3 cases (two in the lung; one in the brain) (Table 1). Various combinations of radical surgery, radiotherapy and chemotherapy were used for cure or palliative care in 62 patients,

Table 1 Clinical data of patients with HNSCC

\begin{tabular}{|c|c|c|c|c|c|}
\hline & $\#(\%)$ & Median age at diagnosis (range) & & Median observation time (range) & \\
\hline Women & $14(21.9 \%)$ & $56.5(48-76)$ years & & 13 (2-53) months & \\
\hline Men & $50(78.1 \%)$ & 57 (34-78) years & & 22 (2-61) months & \\
\hline Deceased & $42(65.6 \%)$ & & & & \\
\hline Status unknown & $3(4.7 \%)$ & & & & \\
\hline Disease reoccurrence & $3(4.7 \%)$ & & & & \\
\hline Tumor locations & \# (\%) & & & & \\
\hline Oral cavity & $34(53.1 \%)$ & & & & \\
\hline Oropharynx & $25(39.1 \%)$ & & & & \\
\hline Hypopharynx & $5(7.8 \%)$ & & & & \\
\hline \multicolumn{6}{|l|}{ TNM classification } \\
\hline Tumor & \# (\%) & Lymph node status & $\#(\%)$ & Distant metastases & \# (\%) \\
\hline $\mathrm{T} 1$ & $8(12.5 \%)$ & No & $22(34.4 \%)$ & MO & $61(95.3 \%)$ \\
\hline $\mathrm{T} 2$ & $16(25.0 \%)$ & N1 or higher & $42(65.6 \%)$ & M1 & $3(4.7 \%)$ \\
\hline T3 & $7(10.9 \%)$ & & & & \\
\hline T4 & $33(51.6 \%)$ & & & & \\
\hline Disease stage & \# (\%) & & Histologic grading & \# (\%) & \\
\hline I & $6(9.4 \%)$ & & grade 1 & $12(18.7 \%)$ & \\
\hline$\|$ & $8(12.5 \%)$ & & grade 2 & $36(56.3 \%)$ & \\
\hline III & $3(4.7 \%)$ & & grade 3 & $16(25.0 \%)$ & \\
\hline IVA & $37(57.8 \%)$ & & & & \\
\hline IVB & 7 (10.9\%) & & & & \\
\hline IVC & $3(4.7 \%)$ & & & & \\
\hline Cancer treatment applied & \# (\%) & & & & \\
\hline Radical surgery & $13(20.3 \%)$ & & & & \\
\hline $\begin{array}{l}\text { Radical surgery \& Chemotherapy } \\
\text { \& Radiotherapy }\end{array}$ & $13(20.3 \%)$ & & & & \\
\hline Radical surgery \& Radiotherapy & $18(28.1 \%)$ & & & & \\
\hline Chemotherapy \& Radiotherapy & $10(15.6 \%)$ & & & & \\
\hline Radiotherapy & $8(12.5 \%)$ & & & & \\
\hline No therapy & $2(3.1 \%)$ & & & & \\
\hline
\end{tabular}


whereas in 2 patients their very poor general condition precluded the treatment of cancer (Table 1).

The aCGH analysis detected a total of 689 CNVs, 438 (63.6\%) were identified as gains (additional copies of genetic material present) and 251 (33.4\%) were losses (deficit of genetic material). Most variations were classified by the BlueFuse Multi software as potentially pathogenic, 483 out of 689 (70.1\%), whereas 50 variations (7.3\%) were declared as benign CNVs and the rest, 156 $(22.6 \%)$ as unknown. The size of variations ranged between the cut-off value of $20 \mathrm{~kb}$ and whole chromosomes. The level of gain/loss, the $\log 2$ ratio, also included a wider range of values, which is clearly the consequence of the presence of tumor DNA with substantial amount of somatic mosaicism. Only 2 samples have not yielded any variations. Summarized data are presented in Table 2.

The association analysis between overlapping genomic regions constructed from obtained variations and stratified clinical data revealed several statistically significant results (Table 3). Each genomic region statistical data is complemented with the range of $\log 2$ ratios values as well as sizes of CNVs that overlap at the particular region. In low stage tumors (stage I and II) a $2.98 \mathrm{Mb}$ region from 6p21.2-p11 and a 7.4 Mb region from 8q11.1q11.23 were overrepresented in comparison to higher stage tumors. Within the latter locus a smaller $1.4 \mathrm{Mb}$ genomic region has a higher association (Table 3).

A $1.1 \mathrm{Mb}$ region on 8q24.13 was overrepresented in welldifferentiated tumors (grade 1) compared to poorly differentiated tumors (grades $2 \& 3$ ). The loss of a large part of a short arm of chromosome 3 was significantly more common in grade 1 tumors. This approximately $80 \mathrm{Mb}$ long continuous region from $3 p$ was found to be associated with a varying degree of statistical significance as indicated in Table 3 (entry loss 1). The data for this genomic region are displayed only as ranges includeing maximal and minimal values from all smaller overlapping genomic regions that constitute the entire entry loss 1 . The loss of further genomic regions associated with well differentiated tumors included a $1.24 \mathrm{Mb}$ region on $6 \mathrm{q} 14.3$ and a $32 \mathrm{Mb}$ terminal region of chromosome 8 (8p23.3).

Furthermore, genomic regions that were significantly overrepresented in cases with lymph node involvement were a gain of $0.75 \mathrm{Mb}$ region on 3q24 and a gain of $0.9 \mathrm{Mb}$ region on 3q26.32-q26.33. Genomic regions overrepresented in cases without lymph node involvement included a gain 1.1 Mb region on 8q23.3.
Additional genomic regions were identified when patients were stratified according the use of surgery for treating of their cancer. On 7q21.3-q22.3 a $12.2 \mathrm{Mb}$ large gain was overrepresented in patients without surgical treatment. A short $0.33 \mathrm{Mb}$ overlapping gain region on $20 \mathrm{q} 11.22$ was also significantly more frequent in patients with no surgical treatment.

No significant overrepresentations of gains or losses were found when tumors were stratified according to their size in TNM classification.

The HPV genetic material was present in 5 samples out of 64. A more detailed characterization of these samples is presented in Table 4.

\section{Discussion}

The role of gains and losses of large chromosomal regions in cancer has been and still is a major field of research. In our study we analyzed possible associations between CNVs and two clinically distinct groups of head and neck squamous cell carcinomas, early disease and locoregionally advanced cancer. We identified 12 regions from 5 different chromosomes to be significantly overrepresented in 4 different subgroups stratified according to selected clinical parameters (Table 3). We consider overrepresentation of gains of two regions from chromosome 3 in cases with confirmed cancer in local lymph nodes to be important. In the first instance, the region of interest contains a known oncogene, PIK3CA (Gain 6, Table 3, Fig. 1), which has a well-established role in cancer development [18]. The product of this gene is a catalytic unit of the PI3K kinase and in most cancer cases harbors activating mutations [19]. The signaling pathway, PI3K/AKT, is also very frequently mutated in HNSCCs [20]. Copy number gain of the PIK3CA region has been documented to be important in HNSCC, but the reported finding [21] is somewhat contradictory to our results because it conferred poor survival to metastatic HNSCCs with unaffected lymph nodes, whereas our study showed more PIK3CA copy number gains in cancers with affected lymph nodes (Table 3). Earlier studies have identified the PIK3CA gains in the HNSCCs [22], as well as in other major cancers; i.e. breast cancer [23], lung cancer [24] or urothelial cancer [25]. However, PIK3CA gains influencing the spreading of metastases to the lymph nodes have not been reported for HNSCCs. The PIK3CA alterations appear to be present in squamous cell carcinomas regardless from which organ they originate [26]. Not surprisingly we were able to associate

Table 2 Summary data on observed copy number variations

\begin{tabular}{lllllll}
\hline & $\#$ & Pathogenic (\%) & Benign (\%) & Unknown (\%) & Log2 range & Size range (bp) \\
\hline Gains & 438 & $321(73.3 \%)$ & $24(5.5 \%)$ & $93(21.2 \%)$ & $0.22-2.82$ & $20,486-155,171,772$ \\
Losses & 251 & $162(64.5 \%)$ & $26(10.4 \%)$ & $63(25.1 \%)$ & $-3.62--0.25$ & $23,615-127,293,063$ \\
\hline
\end{tabular}

2/64 samples without CNVs: male, oropharynx, stage IVA, pT4pN2, survival time 45 months; female, tongue, stage II, pT2pNo, alive after 40 months 
Table 3 Genomic regions associated with specific clinical features in HNSCC patients

\begin{tabular}{|c|c|c|c|c|c|c|c|}
\hline \multicolumn{8}{|c|}{ Stage I\&\|l vs III\&IV } \\
\hline & Locus & $\#$ & OR $(95 \% \mathrm{Cl})$ & $\mathrm{p}(\mathrm{Chi})^{\mathrm{a}}$ & Log2 ratio range & CNV sizes ${ }^{c}$ & \# of genes \\
\hline gain 1 & $\begin{array}{l}\text { chr6: } \\
\text { 38,729,522-41,698,277 }\end{array}$ & $3 / 11$ vs. $0 / 50$ & - & 0.084 & $0.54-0.62$ & $18.6-19.5 \mathrm{Mb}$ & 35 \\
\hline gain 2 & $\begin{array}{l}\text { chr8: } \\
46,942,986-54,391,986\end{array}$ & $4 / 10 \mathrm{vs}, 2 / 48$ & $0.104(0.017-0.649)$ & 0.0232 & $0.29-0.9$ & $1.56-146 \mathrm{Mb}$ & 20 \\
\hline gain 3 & $\begin{array}{l}\text { chr8: } \\
49,091,330-50,447,801\end{array}$ & $6 / 8$ vs. $3 / 47$ & $0.085(0.018-0.411)$ & 0.0021 & $0.29-0.9$ & $1.56-146 \mathrm{Mb}$ & 5 \\
\hline \multicolumn{8}{|c|}{ Histological grade 1 vs. grade $2 \& 3$} \\
\hline & Locus & $\#$ & OR $(95 \% \mathrm{Cl})$ & $\mathrm{p}(\mathrm{Chi})^{\mathrm{a}}$ & Log2 ratio range & CNV sizes ${ }^{c}$ & \# of genes \\
\hline gain 4 & $\begin{array}{l}\text { chr8: } \\
\text { 122,449,344-123,538,355 }\end{array}$ & $5 / 7$ vs. $6 / 46$ & $5.476(1.312-22.851)$ & 0.0385 & $0.28-0.58$ & $1.0-145 \mathrm{Mb}$ & 2 \\
\hline $\operatorname{loss} 1^{b}$ & $\begin{array}{l}\text { chr3: } \\
\text { 93,979-80,817,252 }\end{array}$ & $5 / 7$ vs. $2 / 50 ; 4 / 8$ vs. $3 / 49$ & $\begin{array}{l}17.86(2.891-110.3) \\
8.167(1.532-43.52)\end{array}$ & $0.0011-0.024$ & $-0.64--0.26$ & 1.4-93 Mb & 647 \\
\hline loss 2 & $\begin{array}{l}\text { chr6: } \\
85,683,523-86,925,006\end{array}$ & $2 / 10$ vs. $0 / 52$ & - & 0.0384 & $-0.7--0.26$ & $1.24-40 \mathrm{Mb}$ & 6 \\
\hline loss 3 & $\begin{array}{l}\text { chr8: } \\
221,641-32,847,282\end{array}$ & $3 / 9$ vs. $1 / 51$ & $17(1.587-182.1)$ & 0.0205 & $-0.64--0.26$ & $6.8-43 \mathrm{Mb}$ & 309 \\
\hline \multicolumn{8}{|c|}{ Node lymph involvement vs. cases without affected lymph nodes } \\
\hline & Locus & \# & OR $(95 \% \mathrm{Cl})$ & $p(C h i 2)^{a}$ & Log2 ratio range & CNV sizes ${ }^{c}$ & \# of genes \\
\hline gain 5 & $\begin{array}{l}\text { chr3: } \\
147,963,947-148,708,961\end{array}$ & $9 / 33$ vs. $0 / 22$ & - & 0.0495 & $0.28-0.96$ & $5.6-109 \mathrm{Mb}$ & 3 \\
\hline gain 6 & $\begin{array}{l}\text { chr3: } \\
178,764,078-179,689,394\end{array}$ & $14 / 28$ vs. $1 / 21$ & $9.414(1.141-77.65)$ & 0.0349 & $0.27-0.96$ & $5-109 \mathrm{Mb}$ & 13 \\
\hline gain 7 & $\begin{array}{l}\text { chr8: } \\
\text { 108,460,956-109,567,888 }\end{array}$ & $3 / 39$ vs. $7 / 15$ & $0.165(0.038-0.723)$ & 0.0264 & $0.28-0.8$ & $0.2-146 \mathrm{Mb}$ & 4 \\
\hline \multicolumn{8}{|c|}{ Cases treated with surgery vs. cases without surgical treatment } \\
\hline & Locus & $\#$ & OR $(95 \% \mathrm{Cl})$ & $\mathrm{p}(\mathrm{Chi} 2)^{\mathrm{a}}$ & Log2 ratio range & CNV sizes ${ }^{c}$ & \# of genes \\
\hline gain 8 & $\begin{array}{l}\text { chr7: } \\
92,828,329-105,027,875\end{array}$ & $2 / 42$ vs. $5 / 15$ & $0.143(0.025-0.816)$ & 0.0457 & $0.35-0.83$ & $21-78 \mathrm{Mb}$ & 196 \\
\hline gain 9 & $\begin{array}{l}\text { chr20: } \\
33,690,620-34,021,768\end{array}$ & $0 / 44$ vs. $3 / 17$ & - & 0.0462 & $0.35-0.67$ & $33-34 \mathrm{Mb}$ & 9 \\
\hline
\end{tabular}

\footnotetext{
degree of freedom $=1$

${ }^{b}$ values in categories \# and OR correspond to the $\mathrm{p}(\mathrm{Chi2})$ values which are the lower and upper boundary of observed statistical significance in this region; values in categories Locus, Log2 ratio range and CNV size are range boundaries that do not correspond to the displayed statistical data for the entry loss1 'column CNV sizes displayes the range of sizes of CNVs that include the region of each particular entry
}

a member of a gene signature specific for squamous cell carcinoma with a clinically distinct subtype. It is important to note that the aggressive behavior of tumors with altered PIK3CA gene function is not the only possible consequence, because the role as good prognostic marker is also known for the activated PI3K/AKT signalling pathway [27].

Secondly, the overrepresentation of a region containing the gene for angiotensin II receptor type 1 (AGTR1)
(Gain 5, Table 3, Fig. 1) in HNSCC cases with metastases in local lymph nodes was observed. Although this association was weaker in comparison to previously described PIK3CA association, it nevertheless identified a very interesting gene, AGTR1, as a tumor biomarker for HNSCC. This observation is in line with the increased expression of AGTR1 in head and neck cancer [28]. Also, the AGTR1 gene was found to be implicated in other important cancers, i.e. colorectal or breast cancer $[29,30]$.

Table 4 Clinical characteristics of patients with HPV positive tumor DNA samples

\begin{tabular}{lllllll}
\hline Gender & Age at diagnosis & Tumor location & TNM classification & Histology & Treatment & Status \\
\hline male & 67 & oral cavity & pT4 N0 & grade 3 & surgery, radiotherapy & deceased \\
male & 58 & oropharynx & pT4 pN2 M1 & grade 1 & surgery, radiotherapy & alive \\
male & 51 & oropharynx & T4 N1 & grade 2 & chemotherapy, radiotherapy & alive \\
male & 60 & oral cavity & pT4 pN2 & grade 1 & surgery & deceased \\
male & 55 & oropharynx & pT4 pN2 & grade 3 & surgery, chemotherapy, radiotherapy & deceased \\
\hline
\end{tabular}




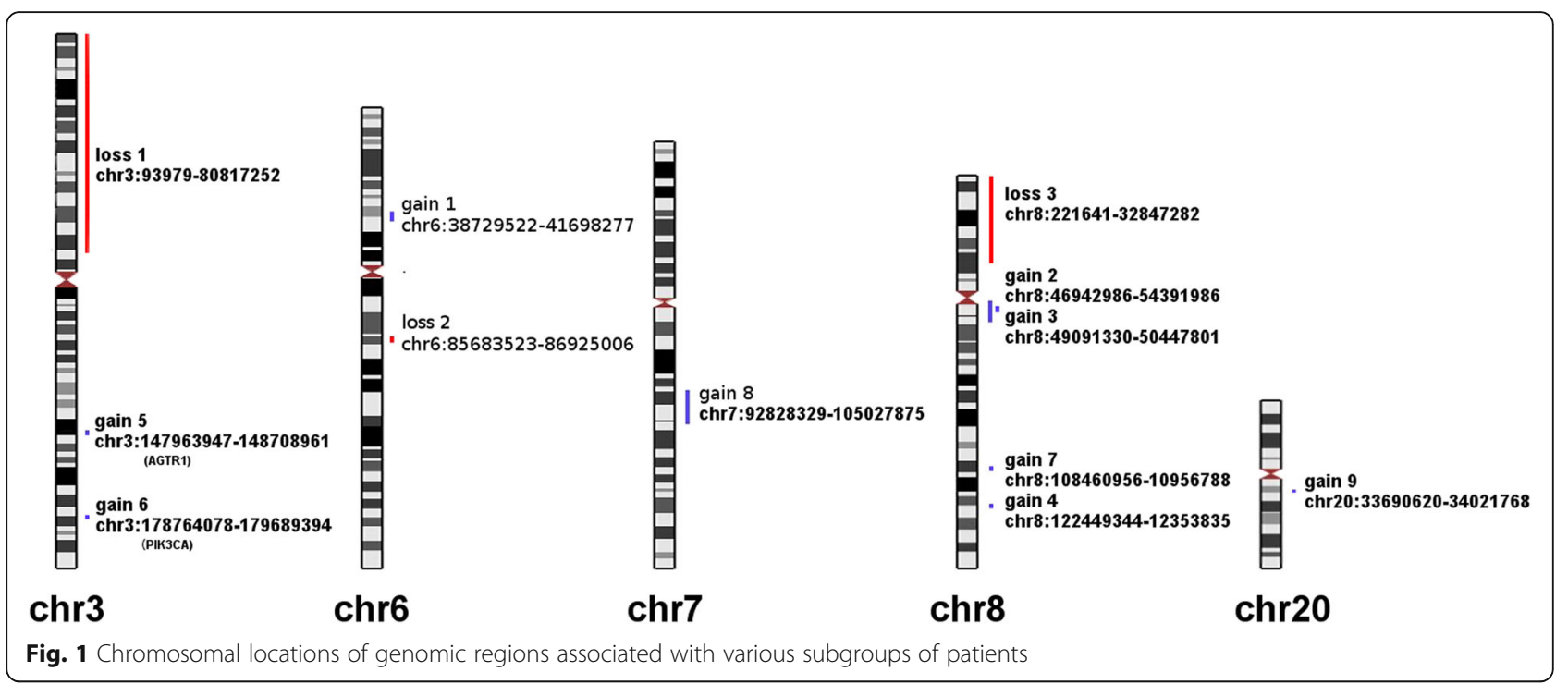

The association of the AGTR1 gene with advanced head and neck cancer is important because it identifies an additional target for chemotherapy as there are several different blocking agents already in use for the treatment of hypertension. Such therapeutic approach was proposed for breast cancer cases overexpressing AGTR1 [31] and the effect of the drugs is known from in-vitro cell line experiments [32]. Because comparable data is not available for head and neck cancers, further inquiries into AGTR1 expression changes and underlying genetic alterations may help establish this gene and its signalling pathway as a legitimate therapeutic target.

We found gains of two genomic regions (Gain 8 and 9, Table 3, Fig. 1) to be overrepresented in a subgroup of patients who have not undergone radical surgery. These individuals either had an inoperable tumor, were in very poor general condition with additional other ailments, or they declined the operation because the procedure was deemed too mutilating. Their tumors were all large lesions with local invasion and extensive lymph node involvement. The first region from chromosome 7 (gain 8) overlaps with the 7q21 chromosomal region previously reported to be present in additional copies in head and neck cancer [33]. Although it contains many interesting genes which are continuously studied with respect to their role in cancer development in an ever increasing body of research, a well-established biomarker has not emerged so far. The second region (Gain 9) is from 20q which has also been implicated in HNSCC [34]. The Gain 9 is a much smaller region than Gain 8 region, but it contains several genes which may contribute to aggressive tumor growth when they are overexpressed. Specific reports for HNSCC may not be available for all the genes of interest but published studies clearly document the cancer involvement for MMP24, EIF6 FAM83C and GDF5 [35-38]. These genes together with the large number of genes from the Gain 8 region warrant further analysis because they are potential biomarkers for aggressive tumor growth.

The remaining genomic regions were all overrepresented in subgroups of patients with a less aggressive or less advanced form of HNSCC. The gains (Gain 1, 2, 3, $4,7)$ and losses (Loss 1, 2, 3) are presented in Table 3 and showed in Fig. 1. Such significant increase, that is not associated with a higher malignancy but with less malignant cases of HNSCC may indicate a possible role in earlier phases of cancer progression. Among the many genes included in the described variations, several genes were already studied for their role in cancer development. For most of these candidate genes the available information does not derine from studies on HNSCC but from studies focusing on other types of cancer. In less advanced cancers with stage I and II the overrepresented region gain 1 contained at least 2 genes of interest: overexpressed TREM2 gene known to be implicated in cell proliferation, was observed in early cases of esophageal cancer $[39,40]$ whereas the TFEB gene, a transcription factor for lysosomal biogenesis, is part of a well- documented cancer specific translocation $\mathrm{t}(6 ; 11)$ [41, 42]. The genomic region Gain 2 from chromosome 8 also contains additional genes important for cancer development. Thus, the overexpression of MCM4 gene was detected in laryngeal squamous cell carcinoma and this gene was also implicated in other cancers because it codes for an important component of the DNA replication machinery $[43,44]$. Inside the genomic region Gain 2 a continuous segment, named Gain 3, was obverved, which showed an even a higher level of association and contained the SNAI2 gene. This is a transcription factor with a demonstrated role as an oncogene in HNSCC [45]. 
Notwithstanding, we did observe overrepresented gains in less malignant cases (stage I \& II) while the gene was found to contribute to poor disease survival [46]. This is contradictory but it may be that an overexpressed SNAI2 is required early in HNSCC development to gain malignant potential.

The largest genomic region exhibiting significant association comprises almost the entire short arm of the chromosome 3 (Loss 1, Table 3, Fig. 1). The loss of this region was overrepresented in well-differentiated grade 1 classified tumors. Thus, our observation identifies a well documented chromosomal aberration as a biomarker for a subgroup of tumors which retained good differentiation. As noted previously, earlier studies identified frequent presence of the $3 p$ deletion in head and neck cancers $[47,48]$. Then the $3 p$ deletion was described in early displastic lesions [49]. More recently, when $p 53$ mutations were detected in combination with $3 p$ deletions worse survival was observed in such cancer cases [50]. Therefore our result identifies a novel facet of this particular genetic alteration, namely its presence in well differentiated HNSCCs, which has not been reported so far.

Furthermore, additional three genomic regions were also overrepresented in well differentiated grade 1 tumors (Table 3, Fig. 1), whereas the Gain 4 region comprises only of 2 possible genes/transcribed regions (HAS2-AS1, LOC105375734) - with little available information. The loss of a region from chromosome 6 (Loss 2) overlaps with a $6 q 14$ region previously described to be deleted in HNSCC [51]. This region was studied for its role in many different cancer types but it was only recently demonstrated that the 2 genes coding for small nuclear RNA, SNORD5OA and SNORD5OB, directly affect the activity of K-Ras, because both snoRNAs bind to it and when deleted, K-Ras activity is increased [52]. Finally, we observed a deletion of the large part of the short arm of chromosome 8 (Loss 3) to be significantly more frequent in grade 1 tumors than in poorly differentiated tumors. This particular aberration is also well known in HNSCC; however, we detected an overabundance in a well differentiated subgroup of tumors which appears to be a novel observation $[47,48]$. The $8 p$ deletions are characteristic for HNSCC but their role is not well understood. Although from other cancers a more malignant behavior was observed when its presence was detected [53].

Our study found several genomic regions (Gain 1, 2, 3, 4, 7, Loss 1, 2, 3; listed in Table 3, presented in Fig. 1) with CNVs to be more frequent in tumor subgroups with less malignant properties. Such findings suggest that certain genetic variations may have a more transitory role in cancer progression. They may be crucial for the tumor to reach a certain stage in its development and are then less important for the further disease course. It is also possible that such variations remain present in the tumor but their existence is masked by the clonal expansion of other cancer cells. Consequently when tumor samples are obtained for a study, relevant sections of tumor may not be included and a single sample from large, advanced tumor may not contain all cancer cell clones. Also the aCGH analysis requires the use of extracted DNA from a highly heterogeneous tumor sample where low percentage CNVs may be masked by normal DNA. The protocol implemented in our study certainly introduced further variability into the analysis of HNSCCs, which are considered highly heterogeneous tumors. As a consequence, it is not particularly surprising that associations were not observed for the most common and typical genomic regions implicated in HNSCC. I.e., the gain of $11 \mathrm{q} 13$ region containing the CCND1 gene, was the most frequent $\mathrm{CNV}$ in our sample for which we did not detect any significant association (data not shown). Several other genomic regions with important genes showed frequent CNVs (i.e. 7p12, EGFR gene) but associations were not present (data not shown) [54]. Such findings can be attributed to a small sample size available for this study which in combination with highly heterogeneous clinical presentation of HNSCC restricts the ability to detect significant associations between genetic markers and clinical parameters. Consequently, we were not able to observe significant differences in survival and this analysis was omitted from the study. In addition, we detected HPV DNA in 5 out of 64 samples (clinical data presented in Table 4) which is significantly below the rate of approximately $20 \%$ reported HNSCC cases in Slovenia [55]. Therefore, it was not possible to detect $\mathrm{CNVs}$ that are specifically associated with the HPV infection and HNSCC.

\section{Conclusions}

This analysis compared frequencies of genomic copy number variations in subgroups of HNSCC patients which were stratified according to clinical parameters characteristic for early or advanced cancer. We identified gains of genomic regions from $3 \mathrm{q}$ containing PIK3CA and AGTR1 genes with significantly higher frequencies in cases with lymph node involvement. The cancer cases which were not treated with surgery also harbored gains of $7 \mathrm{q} 21$ and $20 \mathrm{q}$ genomic regions significantly more often. Interestingly, other gaines and losses with significant associations were overrepresented in subgroups defined by parameters characteristic for early HNSCC. Nevertheless, many different genes could be implicated in HNSCC development and they all represent a potentially important source of biomarkers useful for clinical management of this cancer and targets for further research. 


\section{Abbreviations}

aCGH: Array comparative genomic hybridization; CNV: Copy number variation; HNSCC: Head and neck squamous cell carcinoma; HPV: Human papilloma virus

\section{Acknowledgments}

Not applicable.

\section{Funding}

The study was supported by the University Medical Centre Maibor internal research project IRP-13-01-04.

\section{Availability of data and materials}

The datasets obtained in this study are available from the corresponding author.

\section{Authors' contributions}

B.Z. performed the statistical analysis and drafted the manuscript. D.K. performed DNA extraction, aCGH analysis and helped to draft the manuscript. Š.S.H. performed DNA extraction, HPV typing and helped to draft the manuscript. A.Z. performed aCGH analysis and helped to draft the manuscript. B.C. recruited the patients, provided tumor samples, clinical data for each partcipant and helped to draft the manuscript. N.K.V. designed the study, provided the funding, performed aCGH analysis and helped to draft the manuscript. All authors read and approved the final manuscript.

\section{Ethics approval and consent to participate}

The study was approved by the Ethics committee of the University Medical Centre Maribor, where it was conducted. Each patient signed an informed consent prior to the study enrollment.

\section{Consent for publication}

All the participants accepted with the initial written informed consent the possibility that the results of this study could be published.

\section{Competing interests}

The authors declare that they have no competing interests.

\section{Publisher's Note}

Springer Nature remains neutral with regard to jurisdictional claims in published maps and institutional affiliations.

\section{Author details}

${ }^{1}$ Laboratory of Medical Genetics, University Medical Centre Maribor, Ljubljanska 5, 2000 Maribor, Slovenia. ${ }^{2}$ Department of Otorhinolaryngology, University

Medical Centre Maribor, Ljubljanska 5, 2000 Maribor, Slovenia.

Received: 16 November 2017 Accepted: 3 January 2018

Published online: 15 January 2018

\section{References}

1. Ferlay J, Soerjomataram I, Dikshit R, Eser S, Mathers C, Rebelo M, Parkin DM, Forman D, Bray F. Cancer incidence and mortality worldwide: sources, methods and major patterns in GLOBOCAN 2012. Int J Cancer. 2015; 136:E359-86.

2. Psyrri A, Licitra L, Lacombe D, Schuuring E, Budach W, Ozsahin M, Knecht R, Vermorken JB, Langendijk JA. Strategies to promote translational research within the European Organization for Research and Treatment of cancer (EORTC) head and neck cancer group: a report from the translational research subcommittee. Ann Oncol. 2010;21:1952-60.

3. Schuuring $E$. The involvement of the chromosome $11 \mathrm{q} 13$ region in human malignancies: cyclin D1 and EMS1 are two new candidate oncogenes-a review. Gene. 1995;159:83-96.

4. Kim HS, Chung WB, Hong SH, Kim JA, Na SY, Jang HJ, Sohn YK, Kim JW. Inactivation of p16INK4a in primary tumors and cell lines of head and neck squamous cell carcinoma. Mol Cells. 2000;10:557-65.

5. Riethdorf S, Friedrich RE, Ostwald C, Barten M, Gogacz P, Gundlach KK, Schlechte H, Becker J, Bregenzer T, Riethdorf L, Löning T. p53 gene mutations and HPV infection in primary head and neck squamous cell carcinomas do not correlate with overall survival: a long-term follow-up study. J Oral Pathol Med. 1997;26:315-21.
6. Grandis JR, Tweardy DJ. Elevated levels of transforming growth factor alpha and epidermal growth factor receptor messenger RNA are early markers of carcinogenesis in head and neck cancer. Cancer Res. 1993;53:3579-84.

7. González MV, Pello MF, López-Larrea C, Suárez C, Menéndez MJ, Coto E. Deletion and methylation of the tumour suppressor gene p16/CDKN2 in primary head and neck squamous cell carcinoma. J Clin Pathol. 1997;50: 509-12.

8. Freier K, Knoepfle K, Fleichtenmacher C, Pungs S, Devens F, Toedt G, Hofele C, Joos S, Lichter P, Radlwimmer B. Recurrent copy number gain of transcription factor SOX2 and corresponding high expression in oral squamous cell carcinoma. Genes Chromosome Canc. 2010;49:9-16.

9. Uchida K, Oga A, Mano T, Mihara M, Kawauchi S, Furuya T, Ueyama Y, Sasaki K. Loss of $3 q 26.3$ is an independent prognostic factor in patients with oral squamous cell carcinoma. Oncol Rep. 2011;26:463-9.

10. Hao JJ, Shi ZZ, Zhao ZX, Zhang Y, Gong T, Li CX, Zhan T, Cai Y, Dong JT, SB F, Zhan QM, Wang MR. Characterization of genetic rearrangements in esophageal squamous carcinoma cell lines by a combination of M-FISH and array-CGH: further confirmation of some split genomic regions in primary tumours. BMC Cancer. 2012;12:367.

11. Baldwin C, Garnis C, Zhang L, Rosin MP, Lam WL. Multiple microalterations detected at high frequency in oral cancer. Cancer Res. 2005;65:7561-7.

12. Kaminagakura E, Werneck da Cunha I, Soares FA, Nishimoto IN, Kowalski LP. CCND1 amplification and protein overexpression in oral squamous cell carcinoma of young patients. Head Neck. 2011;33:1413-9.

13. Rainsbury JW, Ahmed W, Williams HK, Roberts S, Paleri V, Mehanna H. Prognostic biomarkers of survival in oropharyngeal squamous cell carcinoma: systematic review and meta-analysis. Head Neck. 2013;35:1048-55.

14. Reiter M, Baumeister P, Hartmann M, Schwenk-Zieger S, Harréus U. Chemoprevention by celecoxib and mutagen sensitivity of cyclin d1 in patients with oropharyngeal carcinoma. In Vivo. 2014;28:49-53.

15. Pan Q, Gorin MA, Teknos TN. Pharmacotherapy of head and neck squamous cell carcinoma. Expert Opin Pharmacother. 2009;10:2291-302.

16. Lunde ML, Roman E, Warnakulasuriya S, Mehrotra R, Laranne J, Vasstrand EN Ibrahim SO. Profiling of chromosomal changes in potentially malignant and malignant oral mucosal lesions from south and South-East Asia using arraycomparative genomic hybridization. Cancer Genomics Proteomics. 2014;11: 127-40.

17. Qu W, Jiang G, Cruz Y, Chang CJ, Ho GY, Klein RS, Burk RD. PCR detection of human papillomavirus: comparison between MY09/MY11 and GP5+/GP6+ primer systems. J Clin Microbiol. 1997;35:1304-10.

18. Lai K, Killingsworth MC, Lee CS. Gene of the month: PIK3CA. J Clin Pathol. 2015:68:253-7.

19. Samuels Y, Waldman T. Oncogenic mutations of PIK3CA in human cancers. Curr Top Microbiol Immunol. 2010;347:21-41.

20. Lui WW, Hedberg ML, Li H, Vangara BS, Pendleton K, Zeng Y, Lu Y, Zhang Q, Du Y, Gilbert BR, Freilino M, Sauerwein S, Peyser ND, Xiao D, Diergaarde B, Wang L, Chiosea S, Seethala R, Johnson JT, Kim S, Duvvuri U, Ferris RL, Romkes M, Nukui T, Kwok-Shing Ng P, Garraway LA, Hammerman PS, Mills GB, Grandis JR. Frequent mutation of the PI3K pathway in head and neck cancer defines predictive biomarkers. Cancer Discov. 2013;3:761-9.

21. Suda T, Hama T, Kondo S, Yuza Y, Yoshikawa M, Urashima M, Kato T, Moriyama H. Copy number amplification of the PIK3CA gene is associated with poor prognosis in non-lymph node metastatic head and neck squamous cell carcinoma. BMC Cancer. 2012;12:416.

22. Liu CJ, Lin SC, Chen YJ, Chang KM, Chang KW. Array-comparative genomic hybridization to detect genomewide changes in microdissected primary and metastatic oral squamous cell carcinomas. Mol Carcinog. 2006:45:721-31.

23. Wu G, Xing M, Mambo E, Huang X, Liu J, Guo Z, Chatterjee A, Goldenberg D, Gollin SM, Sukumar S, Trink B, Sidransky D. Somatic mutation and gain of copy number of PIK3CA in human breast cancer. Breast Cancer Res. 2005;7:R609-16.

24. Toschi L, Finocchiaro G, Nguyen TT, Skokan MC, Giordano L, Gianoncelli L, Perrino M, Siracusano L, Di Tommaso L, Infante M, Alloisio M, Roncalli M, Scorsetti M, Jänne PA, Santoro A, Varella-Garcia M. Increased SOX2 gene copy number is associated with FGFR1 and PIK3CA gene gain in non-small cell lung cancer and predicts improved survival in early stage disease. PLoS One. 2014;9:e95303.

25. Bellmunt J, Werner L, Leow JJ, Mullane SA, Fay AP, Riester M, Van Hummelen P, Taplin ME, Choueiri TK, Van Allen E, Rosenberg J. Somatic copy number abnormalities and mutations in PI3K/AKT/mTOR pathway have prognostic significance for overall survival in platinum treated locally advanced or metastatic Urothelial tumors. PLoS One. 2015;10:e0124711. 
26. Schwaederle M, Elkin SK, Tomson BN, Carter JL, Kurzrock R. Squamousness: next-generation sequencing reveals shared molecular features across squamous tumor types. Cell Cycle. 2015;14:2355-61.

27. Hashimoto K, Tsuda H, Koizumi F, Shimizu C, Yonemori K, Ando M, Kodaira M, Yunokawa M, Fujiwara Y, Tamura K. Activated PI3KJAKT and MAPK pathways are potential good prognostic markers in node-positive, triple-negative breast cancer. Ann Oncol. 2014;25:1973-9.

28. Mitra S, Mukherjee N, Das S, Das P, Panda CK, Chakrabarti J. Anomalous altered expressions of downstream gene-targets in TP53-miRNA pathways in head and neck cancer. Sci Rep. 2014:4:6280.

29. Zhou L, Luo Y, Sato S, Tanabe E, Kitayoshi M, Fujiwara R, Sasaki T, Fuji $K$, Ohmori $H$, Kuniyasu $H$. Role of two types of angiotensin II receptors in colorectal carcinoma progression. Pathobiology. 2014;81:169-75.

30. Rhodes DR, Ateeq B, Cao Q, Tomlins SA, Mehra R, Laxman B, KalyanaSundaram S, Lonigro RJ, Helgeson BE, Bhojani MS, Rehemtulla A, Kleer CG, Hayes DF, Lucas PC, Varambally S, Chinnaiyan AM. AGTR1 overexpression defines a subset of breast cancer and confers sensitivity to losartan, an AGTR1 antagonist. Proc Natl Acad Sci U S A. 2009;106:10284-9.

31. Singh A, Nunes JJ, Ateeg B. Role and therapeutic potential of G-protein coupled receptors in breast cancer progression and metastases. Eur J Pharmacol. 2015;763:178-83.

32. Du N, Feng J, Hu LJ, Sun X, Sun HB, Zhao Y, Yang YP, Ren H. Angiotensin II receptor type 1 blockers suppress the cell proliferation effects of angiotensin II in breast cancer cells by inhibiting AT1R signaling. Oncol Rep. 2012;27:1893-903.

33. Hannen EJ, Macville MV, Wienk SM, Slootweg PJ, Manni JJ, Hanselaar AG, de Wilde PC. Different chromosomal imbalances in metastasized and nonmetastasized tongue carcinomas identified by comparative genomic hybridization. Oral Oncol. 2004;40:364-71.

34. Martin CL, Reshmi SC, Ried T, Gottberg W, Wilson JW, Reddy JK, Khanna P, Johnson JT, Myers EN, Gollin SM. Chromosomal imbalances in oral squamous cell carcinoma: examination of 31 cell lines and review of the literature. Oral Oncol. 2008:44:369-82

35. de la Peña S, Sampieri CL, Ochoa-Lara M, León-Córdoba K, Remes-Troche $\mathrm{JM}$. Expression of the matrix metalloproteases 2, 14, 24, and 25 and tissue inhibitor 3 as potential molecular markers in advanced human gastric cancer. Dis Markers. 2014;2014:285906.

36. Pinzaglia M, Montaldo C, Polinari D, Simone M, La Teana A, Tripodi M, Mancone C, Londei P, Benelli D. EIF6 over-expression increases the motility and invasiveness of cancer cells by modulating the expression of a critical subset of membrane-bound proteins. BMC Cancer. 2015;15:131.

37. Cipriano R, Miskimen KL, Bryson BL, Foy CR, Bartel CA, Jackson MW. Conserved oncogenic behavior of the FAM83 family regulates MAPK signaling in human. Mol Cancer Res. 2014;12:1156-65.

38. Margheri F, Schiavone N, Papucci L, Magnelli L, Serratì S, Chillà A, Laurenzana A, Bianchini F, Calorini L, Torre E, Dotor J, Feijoo E, Fibbi G, Del Rosso M. GDF5 regulates TGFß-dependent angiogenesis in breast carcinoma MCF-7 cells: in vitro and in vivo control by anti-TGFß peptides. PLoS One. 2012;7:e50342

39. Wang XQ, Tao BB, Li B, Wang XH, Zhang WC, Wan L, Hua XM, Li ST. Overexpression of TREM2 enhances glioma cell proliferation and invasion: a therapeutic target in human glioma. Oncotarget. 2016;7:2354-66.

40. Warnecke-Eberz U, Metzger R, Hölscher AH, Drebber U, Bollschweiler E. Diagnostic marker signature for esophageal cancer from transcriptome analysis. Tumour Biol. 2016;37:6349-58.

41. Sardiello M, Palmieri M, di Ronza A, Medina DL, Valenza M, Gennarino VA, D Malta C, Donaudy F, Embrione V, Polishchuk RS, Banfi S, Parenti G, Cattaneo E, Ballabio AA. Gene network regulating lysosomal biogenesis and function. Science. 2009;325:473-7.

42. Tan PH, Cheng L, Rioux-Leclercq N, Merino MJ, Netto G, Reuter VE, Shen SS, Grignon DJ, Montironi R, Egevad L, Srigley JR, Delahunt B, Moch H, Renal Tumor ISUP. Panel. Renal tumors: diagnostic and prognostic biomarkers. Am J Surg Pathol. 2013;37:1518-31.

43. Lian M, Fang J, Han D, Ma H, Feng L, Wang R, Yang F. Microarray gene expression analysis of tumorigenesis and regional lymph node metastasis in laryngeal squamous cell carcinoma. PLoS One. 2013;8:e84854

44. Bruck I, Perez-Arnaiz P, Colbert MK, Kaplan DL. Insights into the initiation of eukaryotic DNA replication. Nucleus. 2015;6(6):449-54.

45. Katafiasz D, Smith LM, Wahl JK 3rd. Slug (SNAI2) expression in oral SCC cells results in altered cell-cell adhesion and increased motility. Cell Adhes Migr. 2011;5:315-22
46. Zhang J, Cheng Q, Zhou Y, Wang Y, Chen X. Slug is a key mediator of hypoxia induced cadherin switch in HNSCC: correlations with poor prognosis. Oral Oncol. 2013;49:1043-50.

47. Hermsen MA, Joenje H, Arwert F, Braakhuis BJ, Baak JP, Westerveld A, Slater R. Assessment of chromosomal gains and losses in oral squamous cell carcinoma by comparative genomic hybridisation. Oral Oncol. 1997;33:414-8.

48. Garnis C, Baldwin C, Zhang L, Rosin MP, Lam WL. Use of complete coverage array comparative genomic hybridization to define copy number alterations on chromosome 3p in oral squamous cell carcinomas. Cancer Res. 2003;63: 8582-5.

49. Chakraborty SB, Dasgupta S, Roy A, Sengupta A, Ray B, Roychoudhury S, Panda CK. Differential deletions in $3 p$ are associated with the development of head and neck squamous cell carcinoma in Indian patients. Cancer Genet Cytogenet. 2003;146:130-8.

50. Gross AM, Orosco RK, Shen JP, Egloff AM, Carter H, Hofree M, Choueiri M, Coffey CS, Lippman SM, Hayes DN, Cohen EE, Grandis JR, Nguyen QT, Ideker T. Multi-tiered genomic analysis of head and neck cancer ties TP53 mutation to 3p loss. Nat Genet. 2014;46:939-43.

51. Wreesmann VB, Shi W, Thaler HT, Poluri A, Kraus DH, Pfister D, Shaha AR, Shah JP, Rao PH, Singh B. Identification of novel prognosticators of outcome in squamous cell carcinoma of the head and neck. J Clin Oncol. 2004;22:3965-72.

52. Siprashvili Z, Webster DE, Johnston D, Shenoy RM, Ungewickell AJ, Bhaduri A, Flockhart R, Zarnegar BJ, Che Y, Meschi F, Puglisi JD, Khavari PA. The noncoding RNAs SNORD50A and SNORD50B bind K-Ras and are recurrently deleted in human cancer. Nat Genet. 2016;48:53-8.

53. Lebok P, Mittenzwei A, Kluth M, Özden C, Taskin B, Hussein K, Möller K, Hartmann A, Lebeau A, Witzel I, Mahner S, Wölber L, Jänicke F, Geist S, Paluchowski P, Wilke C, Heilenkötter U, Simon R, Sauter G, Terracciano L, Krech $\mathrm{R}$, von der Assen A, Müller V, Burandt E. 8p deletion is strongly linked to poor prognosis in breast cancer. Cancer Biol Ther. 2015;16:1080-7.

54. The Cancer Genome Atlas Network. Comprehensive genomic characterization of head and neck squamous cell carcinomas. Nature. 2015;517:576-82.

55. Strojan P, Zadnik V, Šifrer R, Lanišnik B, Didanović V, Jereb S, Poljak M, Kocjan BJ, Gale N. Incidence trends in head and neck squamous cell carcinoma in Slovenia, 1983-2009: role of human papillomavirus infection. Eur Arch Otorhinolaryngol. 2015;272:3805-14.

\section{Submit your next manuscript to BioMed Central and we will help you at every step:}

- We accept pre-submission inquiries

- Our selector tool helps you to find the most relevant journal

- We provide round the clock customer support

- Convenient online submission

- Thorough peer review

- Inclusion in PubMed and all major indexing services

- Maximum visibility for your research

Submit your manuscript at www.biomedcentral.com/submit
) Biomed Central 